\title{
Dendritic cell profiles in the inflamed colonic mucosa predict the responses to tumor necrosis factor alpha inhibitors in inflammatory bowel disease
}

\author{
Natasa Smrekar1, David Drobne1, Lojze M. Smid¹, Ivan Ferkolj¹, Borut Stabuc, Alojz Ihan², \\ Andreja Natasa Kopitar²
}

${ }^{1}$ Department of Gastroenterology and Hepatology, University Medical Centre, Ljubljana, Slovenia

${ }^{2}$ Institutes of Microbiology and Immunology, Faculty of Medicine, University of Ljubljana, Slovenia

Radiol Oncol 2018; 52(4): 443-452.

Received 12 September 2018

Accepted 25 October 2018

Correspondence to: Assist. Prof. Andreja Nataša Kopitar, Institute of Microbiology and Immunology, Faculty of Medicine, University of Ljubljana, Zaloška 4, SI-1000 Ljubljana, Slovenia. Phone: +386 154374 84, Fax: +386 154374 85; E-mail: andreja-natasa.kopitar@mf.uni-lj.si

Disclosure: No potential conflicts of interest were disclosed.

Background. Dendritic cells play crucial roles in the control of inflammation and immune tolerance in the gut. We aimed to investigate the effects of tumor necrosis factor alpha (TNFa) inhibitors on intestinal dendritic cells in patients with inflammatory bowel disease and the potential role of intestinal dendritic cells in predicting the response to treatment.

Patients and methods. Intestinal biopsies were obtained from 30 patients with inflammatory bowel disease before and after treatment with TNFa inhibitors. The proportions of lamina propria dendritic cell phenotypes were analysed using flow cytometry. Disease activity was endoscopically assessed at baseline and after the induction treatment.

Results. At baseline, the proportion of conventional dendritic cells was higher in the inflamed mucosa $(7.8 \%) \mathrm{com}$ pared to the uninflamed mucosa $(4.5 \%)(p=0.003)$, and the proportion of $\mathrm{CD}_{103^{+}}$dendritic cells was lower in the inflamed mucosa $(47.1 \%)$ versus the uninflamed mucosa $(57.3 \%)(p=0.03)$. After 12 weeks of treatment, the proportion of conventional dendritic cells in the inflamed mucosa decreased from $7.8 \%$ to $4.5 \%(p=0.014)$, whereas the proportion of $\mathrm{CDIO}^{+}$dendritic cells remained unchanged. Eighteen out of $30(60 \%)$ patients responded to their treatment by week 12. Responders had a significantly higher proportion of conventional dendritic cells $(9.16 \%$ vs $4.4 \%, p<0.01)$ with higher expression of HLA-DR (median fluorescent intensity [MFI] 12152 vs $8837, p=0.038$ ) in the inflamed mucosa before treatment compared to nonresponders.

Conclusions. A proportion of conventional dendritic cells above $7 \%$ in the inflamed inflammatory bowel disease mucosa before treatment predicts an endoscopic response to TNFa inhibitors.

Key words: inflammatory bowel disease; dendritic cells; tumor necrosis factor-alpha inhibitors; colon cancer

\section{Introduction}

Inflammatory bowel disease (IBD) is a chronic progressive disorder of the gastrointestinal tract with multifactorial pathogenesis. It results from a complex interplay between genetic susceptibility, environmental factors, epithelial barrier defects and altered gut microbiota, which together lead to a dysregulated immune response. ${ }^{1}$
Dendritic cells (DCs) play a central role in the pathogenesis of IBD by maintaining immune homeostasis by regulating the intestinal T-cell response..$^{2-5}$ DC activation and maturation occurs after exposure to microbial stimuli or proinflammatory cytokines, such as tumor necrosis factor alpha (TNFa). ${ }^{6-8}$ Stimulation is followed by the upregulation of the expression of the costimulatory and activation molecules CD80, CD86, CD83, and HLA-DR 
and the promotion of inflammation by the release of various cytokines. ${ }^{6-10}$ DCs obtain the ability to polarize naive T-cells into type $1 \mathrm{~T}$ helper (Th1), type $2 \mathrm{~T}$ helper (Th2), type $17 \mathrm{~T}$ helper (Th17) or T-regulatory (Treg) cells after maturation. ${ }^{11}$ The inflammatory microenvironment (immune cells and cytokines, such as TNFa) in IBD has many similarities to the cancer microenvironment. The interaction between cytokines and the immune response plays major roles in inflammation and colitis-associated cancer. ${ }^{12}$

The gastrointestinal mucosa contains an extensive network of conventional dendritic cells ( $\mathrm{cDCs}$ ) and plasmacytoid dendritic cells (pDCs) that maintain immune tolerance towards luminal antigens in the healthy mucosa. ${ }^{4,13-16}$ It is hypothesized that disturbances in the proportions of pDCs and CDCs and changes in their phenotypes drive uncontrolled inflammation in IBD. Several studies have shown a lack of immature DCs in the peripheral blood of IBD patients and an increased number of activated DCs in the inflamed gut tissue. ${ }^{17-20} \mathrm{~A}$ high concentration of TNFa in the inflamed mucosa drives the activation of DCs. ${ }^{21-23}$ TNFa inhibitors, such as infliximab and adalimumab, induce mucosal healing in patients with IBD by suppressing TNFa driven DC activation. ${ }^{24,25}$

Current treatment goals are the induction and maintenance of remission to provide a better quality of life, to reduce the need for long-term corticosteroid use and to reduce the incidence of negative long-term outcomes such as colorectal carcinoma (CRC). ${ }^{26}$ Over the past thirty years, the overall risk of IBD-associated CRC has declined, and one of the reasons may be effective medical therapy for IBD. ${ }^{27}$ Therefore, it has been proposed that effective disease control and successful mucosal healing may reduce the CRC risk in individual patients with IBD. ${ }^{26}$

TNFa inhibitors have revolutionized the treatment of IBD. They are able to induce and maintain mucosal healing in patients with IBD and therefore may provide additional chemoprevention by reducing long-standing chronic inflammation. However, up to $40 \%$ of patients fail to respond to this therapy ${ }^{28}$ and the mechanism of primary resistance is not known. We have therefore focused our study on the role of DCs in primary resistance to TNFa inhibitors. We also believe that understanding primary resistance to TNFa inhibitors is important for the prevention of IBD-associated CRC.

The primary aim of our study was to evaluate the impact of TNFa inhibitors on the proportions and phenotypes of DCs in the colonic mucosa in IBD. Furthermore, we also studied whether patients who respond to treatment have different proportions and phenotypes of DCs in the mucosa before or after treatment compared with those who do not respond.

\section{Patients and methods}

\section{Patients}

In this prospective study, we included 30 consecutive patients with IBD (16 Crohn's disease (CD) and 14 ulcerative colitis (UC) patients) and 10 healthy individuals (with a normal ileocolonoscopy performed for colorectal cancer screening without any clinical, biochemical or endoscopic signs of inflammation).

All included IBD patients were refractory or intolerant to conventional immunesuppressives, such as thiopurines or methotrexate and were also naïve to TNFa inhibitors at the time of inclusion (Table 1). Disease activity was assessed clinically (simple clinical colitis activity index [SCCAI] for ulcerative colitis and the Harvey Bradshaw severity index [HBSI] for Crohn's disease), biochemically and endoscopically at baseline and again after completing treatment at week $12 . .^{29-32}$ Active disease was defined for ulcerative colitis as a SCCAI score ${ }^{3} 3$ and for Crohn's disease as an HBSI $\geq 5$. Biochemical activity assessment included the measurement of C-reactive protein (CRP) (ADVIA 1800 Chemistry System, Siemens) and faecal calprotectin levels (Calprest assay with a range from $15.6 \mathrm{mg} / \mathrm{kg}$ - $500 \mathrm{mg} / \mathrm{kg}$, Eurospital, Trieste, Italy). Endoscopic disease activity (defined as SES-CD $\geq 3$ or Mayo endoscopic score $\geq 2$ ) was confirmed in all patients with ileocolonoscopies at the time of inclusion. 33,34

\section{Induction treatment and the assessment of responses}

All included patients received induction treatment with TNFa inhibitors (infliximab in 13 patients and adalimumab in 17 patients). Infliximab was administered intravenously at a dose of $5 \mathrm{mg} / \mathrm{kg}$ at baseline, followed by infusions at week 2 and week 6 . Adalimumab was administered subcutaneously at a dose of $160 \mathrm{mg}$ at baseline, followed by $80 \mathrm{mg}$ at week 2 and $40 \mathrm{mg}$ every other week thereafter. ${ }^{35}$ The doses of the TNFa inhibitors were not optimized during induction. The dose of azathioprine was kept stable during induction, but corticoster- 
TABLE 1. Demographic data of the patients and healthy controls enrolled in the study

\begin{tabular}{|c|c|c|}
\hline & $\begin{array}{l}\text { Number } \\
\text { (n) }\end{array}$ & $\begin{array}{l}\text { Mean } \\
\text { (SD) }\end{array}$ \\
\hline Number & 40 & \\
\hline Crohn's disease & 16 & \\
\hline Female/male & $8 / 8$ & \\
\hline Age (years) & & $\begin{array}{c}38.6 \\
(13.7)\end{array}$ \\
\hline Disease duration (years) & & $7.1(6.5)$ \\
\hline Age at diagnosis (years) & & $\begin{array}{c}31.4 \\
(14.5)\end{array}$ \\
\hline Smokers & 5 & \\
\hline Ex-smokers & 3 & \\
\hline Nonsmokers & 8 & \\
\hline $\begin{array}{l}\text { Location of Crohn's disease } \\
\text { I. L1 (ileal) } \\
\text { II. L2 (colonic) } \\
\text { III. L3 (ileocolonic) } \\
\text { IV. L4 (isolated upper disease) }\end{array}$ & $\begin{array}{l}16 \\
0 \\
7 \\
9 \\
0\end{array}$ & \\
\hline $\begin{array}{l}\text { Concomitant medications } \\
\text { I. Aminosalicylates } \\
\text { II. Corticosteroid } \\
\text { III. Azathioprine } \\
\text { IV. Azathioprine + corticosteroids } \\
\text { V. None }\end{array}$ & $\begin{array}{l}13 \\
0 \\
1 \\
9 \\
3 \\
3\end{array}$ & \\
\hline Ulcerative colitis & 14 & \\
\hline Female/male & $8 / 6$ & \\
\hline Age (years) & & $39.2(12)$ \\
\hline Disease duration (years) & & $5.6(2.8)$ \\
\hline Age at diagnosis (years) & & $\begin{array}{c}33.5 \\
(11.7)\end{array}$ \\
\hline Smokers & 1 & \\
\hline Ex-smokers & 3 & \\
\hline Nonsmokers & 10 & \\
\hline $\begin{array}{l}\text { Extent of ulcerative colitis } \\
\text { I. E1 (proctitis) } \\
\text { II. E2 (left sided) } \\
\text { II. E3 (extensive) }\end{array}$ & $\begin{array}{l}14 \\
1 \\
5 \\
8\end{array}$ & \\
\hline $\begin{array}{l}\text { Concomitant medications } \\
\text { I. Aminosalicylates } \\
\text { II. Corticosteroid } \\
\text { III. Azathioprine } \\
\text { IV. Azathioprine + corticosteroids } \\
\text { V. None }\end{array}$ & $\begin{array}{l}14 \\
3 \\
5 \\
3 \\
3 \\
0\end{array}$ & \\
\hline Healthy controls & 10 & \\
\hline Female & 6 & \\
\hline Male & 4 & \\
\hline Age (years) & & $\begin{array}{l}58.3 \\
(9.4)\end{array}$ \\
\hline
\end{tabular}

oid doses were tapered after starting the TNFa inhibitors.

An endoscopic response to induction at week 12 was defined by a Mayo endoscopic sub score of 0 to 1 in ulcerative colitis or $\geq 50 \%$ decrease in the SES-CD from the baseline colonoscopy in Crohn's disease.

\section{Mucosal biopsies and the characterization of the lamina propria dendritic cells}

In total, 40 pinch biopsies were obtained from each IBD patient during the study. Twenty were collected during the baseline colonoscopy (10 biopsies from the inflamed colonic mucosa and 10 from the uninflamed mucosa). The remaining 20 biopsies were obtained from the same colonic segments on week 12 after the induction treatment was completed.

One colonoscopy was performed on each healthy control. We performed 10 biopsies per colonoscopy from all colonic segments.

All colonic tissue samples were obtained with biopsy forceps and placed in containers with normal saline. We started the dissociation of DCs within 3 hours of sample collection. The intestinal biopsies were dissociated into single-cell suspensions by combining mechanical dissociation with enzymatic degradation as previously described. ${ }^{36}$ Briefly, the intraepithelial cells were isolated by incubating the biopsies for $20 \mathrm{~min}$ at $37^{\circ} \mathrm{C}$ with HBSS-EDTA two times (Gibco, Paisley, Scotland, $\mathrm{UK}$ ) (HBSS without $\mathrm{Ca} 2+$ or $\mathrm{Mg} 2+$ and containing 5\% FCS, $10 \mathrm{mM}$ Hepes, $5 \mathrm{mM}$ EDTA and $1 \mathrm{mM}$ DTT) (Sigma-Aldrich, St. Louis, USA). The lamina propria (LP) mononuclear cells (LPMCs) were isolated by digesting the biopsies in HBSS containing 5\% FCS, $1.25 \mathrm{mg} / \mathrm{ml}$ collagenase D (Roche, Basel, Switzerland), $1 \mathrm{mg} / \mathrm{ml}$ collagenase VIII (Sigma-Aldrich, St. Louis, USA), $1 \mathrm{mg} / \mathrm{ml}$ DNase I (Roche, Basel, Switzerland), and $1 \mathrm{mg} / \mathrm{ml}$ Dispase (Invitrogen, Oslo, Norway) for $30 \mathrm{~min}$ at $37^{\circ} \mathrm{C}$ with agitation. Following the digestion, the biopsies were further disrupted using a GentleMACS ${ }^{\circledR}$ dissociator (Miltenyi Biotec, Bergisch Gladbach, Germany). The supernatants were collected by filtering the cell suspensions through nylon mesh, and single-cell suspensions of lamina propria MNCs were enriched for CD45+ cells by magnetic-activated cell sorting (MACS) (Miltenyi Biotec, Bergisch Gladbach, Germany). The cells were washed twice in staining buffer (BD Pharmingen, San Diego, USA) and stained with fluorochrome-conjugated antibodies for $30 \mathrm{~min}$ at $4^{\circ} \mathrm{C}$ in the dark.

We used the following antibodies: anti-HLA-DR APC-Cy7/FITC, anti-CD3 PerCP Cy5.5, anti-CD19 PerCP Cy5.5, anti-CD16 PerCP Cy5.5, anti-CD14 PerCP Cy5.5, anti-CD11c PE/APC, anti-CD11b PE, anti-CD123 PE/PE Cy7, anti-CD303 FITC, anti-CD103 FITC, anti-CD80 FITC/APC, anti-CD83 PE, and anti-CD86 BD Horizon V450/PE-Cy7. All antibodies were obtained from BD Biosciences 
(A)

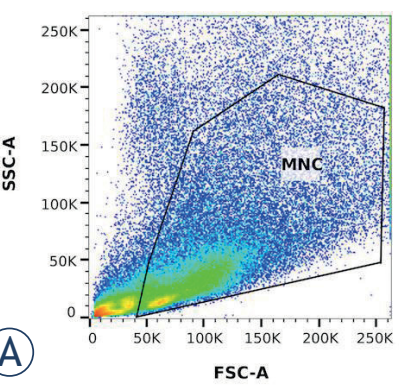

(B)
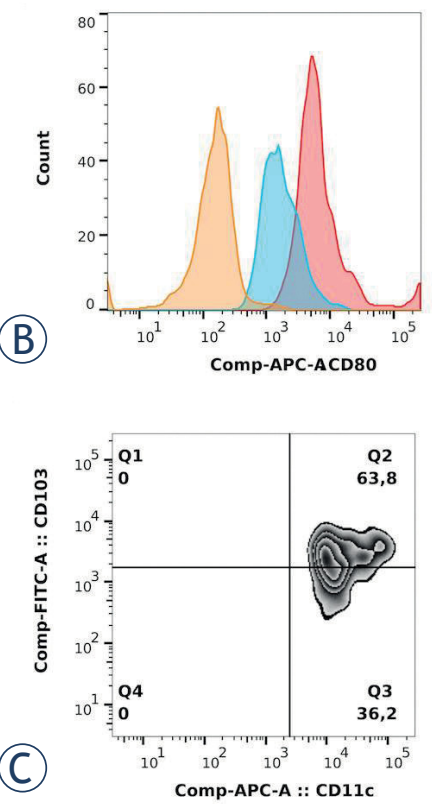
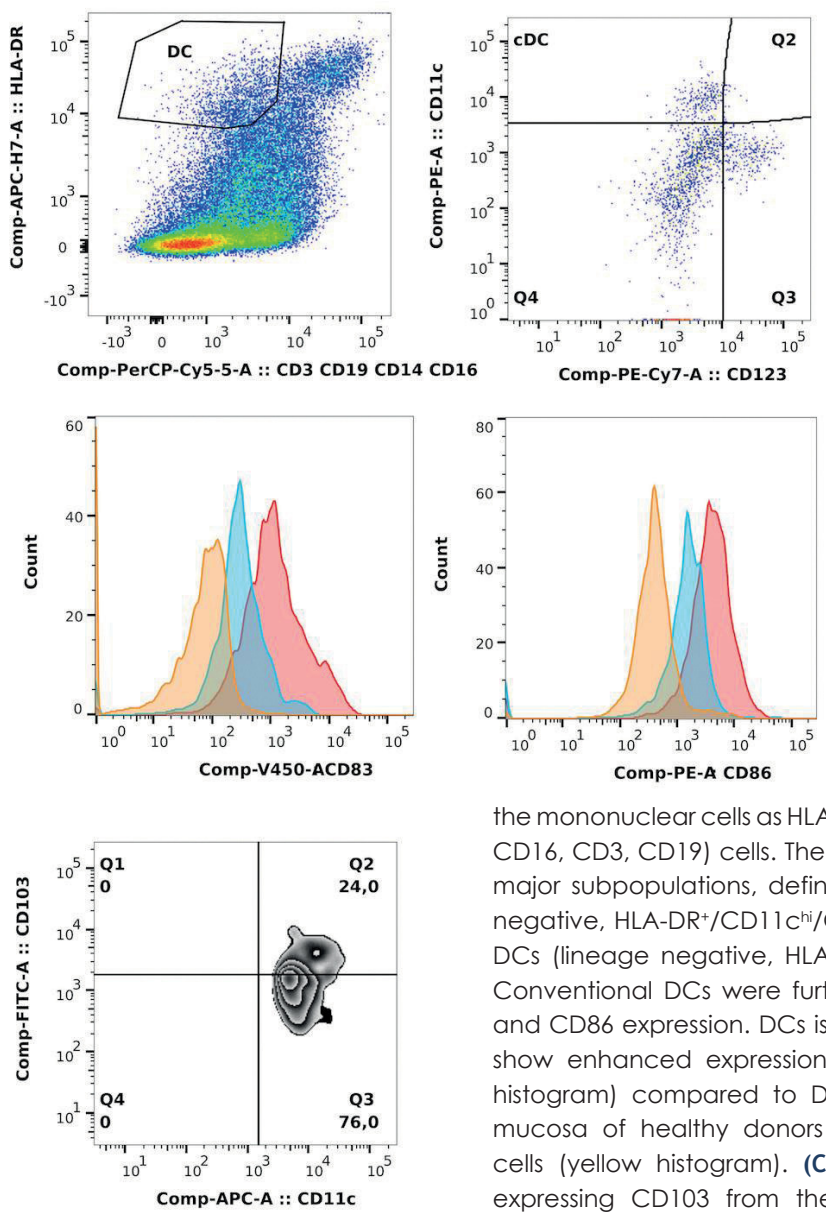

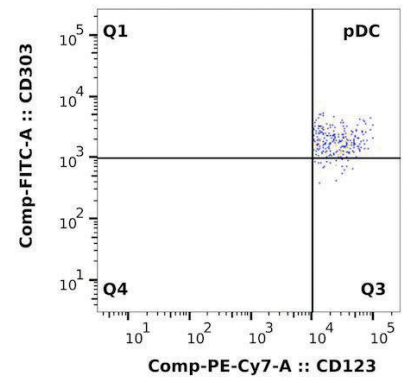

FIGURE 1. Dendritic cell (DC) phenotypes: DCs were isolated from the lamina propria by enzymatic degradation and mechanical dissociation. Data were analysed using FlowJo software. (A) Mononuclear cells were identified within the total cell population (based on the forward/side scatter properties). Total DCs were identified among the mononuclear cells as HLA-DR+ and lineage negative (CD14, CD16, CD3, CD19) cells. The DCs were further divided into two major subpopulations, defined as conventional DCs (lineage negative, HLA-DR+/CD $\left.11 \mathrm{C}^{\text {hi }} / \mathrm{CD} 123-\mathrm{CD} 303-\right)$ and plasmacytoid DCs (lineage negative, HLA-DR $/$ CD $11 \mathrm{C}^{-} / \mathrm{CD}_{123} / \mathrm{CD}^{+} 33^{+}$). (B) Conventional DCs were further investigated for CD80, CD83, and CD86 expression. DCs isolated from the inflamed mucosa show enhanced expression of CD80, CD86 and CD83 (red histogram) compared to DCs isolated from the uninflamed mucosa of healthy donors (blue histogram) and unstained cells (yellow histogram). (C) Examples of conventional DCs expressing CD103 from the uninflamed mucosa (left) and inflamed mucosa (right).
(San Diego, USA) except the anti-CD103 (Dako, Glostrup, Denmark), anti-CD80, anti-CD83, and anti-CD303 (Miltenyi Biotec, Bergisch Gladbach, Germany) antibodies.

Lamina propria DCs were analysed on a BD Canto II flow cytometer (BD Biosciences, San Diego, USA) using DIVA software (BD Biosciences, San Diego, USA). The proportion of cells positive for a given marker was determined by referencing unstained cells. FMO (fluorescence minus one) controls were used to identify and gate cells. A total of 50000 cells were acquired. The data analysis was performed using FlowJo version 10.1 software (TreeStar, Ashland, USA) as previously described. ${ }^{37}$ Lamina propria DCs were identified as HLA-DR-positive and lineage cocktail (CD3/CD14/CD16/CD19)negative cells. The data for $\mathrm{pDCs}$ and $\mathrm{CDCs}$ are presented as the frequency within the lamina propria mononuclear cells. CD103 $/$ CD103- DC data is presented as the frequency among the cDCs. The expression of HLA-DR, CD86, CD80 and CD83 on $\mathrm{CDCs}$ is given as the median fluorescent inten- sity (MFI) (Figure 1). Table 2 describes the surface markers of the measured DC populations.

\section{Statistical analysis}

SPSS 17.0 software (IBM) and GraphPad Prism 6.0 software (GraphPad Software) were used to perform all appropriate statistical analyses. The data are presented as the mean and standard error of the mean. Differences between independent groups were analysed with an unpaired Student's t-test. Predictive cut-off values were identified using receiver operating characteristics (ROC) curve analysis. A p value $<0.05$ was considered statistically significant.

\section{Ethical considerations}

All patients and volunteers gave informed consent for the study. The National Ethics Committee approved the study protocol with the registration number 129/06/13. 
TABLE 2. Phenotypes of the measured dendritic cells (DC)

\begin{tabular}{|c|c|c|}
\hline & Abbreviation & Phenotype \\
\hline Plasmacytoid DC & $\mathrm{pDC}$ & 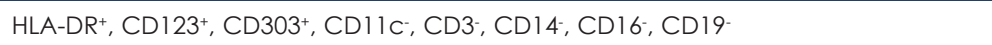 \\
\hline Conventional DC & CDC & 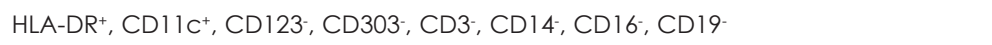 \\
\hline Mature conventional DC & $C D 86^{+} \mathrm{DC}$ & 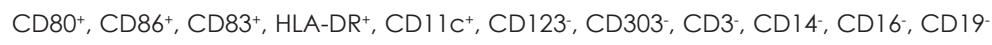 \\
\hline Activated mature conventional DC & HLA-DR DC & HLA-DRhi, CD83+, CD80+, CD86+, CD $11 \mathrm{C}^{+}, \mathrm{CD} 123-\mathrm{CD} 303, \mathrm{CD} 3, \mathrm{CD} 14, \mathrm{CD} 16, \mathrm{CD} 19$ \\
\hline $\begin{array}{l}\text { Intestinal CD } 103^{+} \mathrm{DC} \text { important } \\
\text { in maintaining intestinal immune } \\
\text { homeostasis }\end{array}$ & CD103+ DC & $\mathrm{CD}_{103}+\mathrm{HLA}^{-\mathrm{DR}}+, \mathrm{CD} 11 \mathrm{C}^{+}, \mathrm{CD} 123, \mathrm{CD} 303, \mathrm{CD} 3, \mathrm{CD} 14, \mathrm{CD} 16, \mathrm{CD} 19-$ \\
\hline
\end{tabular}

\section{Results}

\section{Clinical outcomes}

An endoscopic response to treatment was observed in 7/14 (50\%) patients with UC and 11/16 (69\%) CD patients at week 12 (Table 3 ). CRP and faecal calprotectin concentrations decreased following the induction treatment. However, neither the baseline CRP nor the baseline faecal calprotectin concentration was predictive of the response to treatment, data not shown.

\section{Proportions of dendritic cells in the colonic mucosa}

We analysed biopsies from 59 colonoscopies from 30 patients (29 patients had colonoscopies performed before and after treatment, while one patient only had a baseline endoscopy performed). The proportions of the $\mathrm{pDC}, \mathrm{cDC}$ and CD103- DC subsets were higher in the inflamed mucosa of IBD patients compared to the mucosa of healthy controls. However, the proportion of the CD103+ subset was lower in the inflamed mucosa than in the mucosa of healthy controls (Table 4).

At baseline, the proportion of cDCs was higher in the inflamed mucosa compared to the uninflamed mucosa of IBD patients, but the proportion of the $\mathrm{CD}_{103}{ }^{+} \mathrm{DC}$ subset was lower in the inflamed mucosa (Table 5).

When comparing the pretreatment inflamed mucosa of UC and CD patients, we found no differences in the proportions of the $\mathrm{pDC}, \mathrm{cDC}, \mathrm{CD}_{103^{+}}$ and CD103- DCs subsets, and we did not observe any differences in the expression of the costimulatory molecule CD86.

\section{Effect of the treatment with TNFa antagonists on DC expression patterns}

The proportion of cDCs decreased after the treatment with TNFa inhibitors in the inflamed mucosa,
TABLE 3. Clinical, biochemical and endoscopic data of the patients before and after treatment with TNFa inhibitors

\begin{tabular}{lcc}
\hline & $\begin{array}{c}\text { Before treatment } \\
\text { (week 0) }\end{array}$ & $\begin{array}{c}\text { After treatment } \\
\text { (week 12) }\end{array}$ \\
\hline ULCERATIVE COLITIS $(\mathbf{n}=14)$ & $8.4(0.9)$ & $3.1(0.5)$ \\
SCCAI & $8.8(2.9)$ & $7.8(2.4)$ \\
CRP $(\mathrm{mg} / \mathrm{l})$ & $351(41.7)$ & $254(58.2)$ \\
Fecal calprotectin $(\mathrm{mg} / \mathrm{kg})$ & $2.4(0.1)$ & $1.5(0.3)$ \\
Endoscopic Mayo Score & & \\
CROHN'S DISEASE $(\mathbf{n}=16)$ & $9.5(1.3)$ & $3.3(0.8)$ \\
HBSI & $17.5(3.1)$ & $10.5(3.6)$ \\
CRP (mg/l) & $341(40)$ & $209(48)$ \\
Fecal calprotectin $(\mathrm{mg} / \mathrm{kg})$ & $12.9(1.1)$ & $5.5(1.8)$ \\
SES-CD & & \\
\hline
\end{tabular}

The data are presented as the mean and standard error of the mean.

$\mathrm{CRP}=\mathrm{C}$-reactive protein; $\mathrm{HBSI}=$ Harvey Bradshaw severity index; $\mathrm{SCCAI}=$ simple clinical colitis activity index: SES-CD = simple endoscopic score for Crohn disease

TABLE 4. Subpopulations of dendritic cells (DC) in the inflamed inflammatory bowel disease (IBD) mucosa and the mucosa of healthy controls (HC) before the treatment with TNFa inhibitors

\begin{tabular}{lccc} 
& IBD-inflamed & HC & p value \\
\hline pDC (\%) & $1.7(0.3)$ & $0.3(0.1)$ & 0.005 \\
CDC (\%) & $7.8(0.9)$ & $0.5(0.1)$ & $<0.001$ \\
CD86 (MFI) & $1248(231)$ & $430(43)$ & 0.04 \\
HLA-DR (MFI) & $10918(767)$ & $11808(711)$ & 0.52 \\
CD103+(\%) & $47.1(3.1)$ & $66.3(3.3)$ & 0.002 \\
CD103- (\%) & $52.8(3.2)$ & $32.1(4.1)$ & 0.001 \\
\hline
\end{tabular}

Proportion and median fluorescence intensity (MFI) of plasmacytoid DCs (pDCs) and conventional DCs (CDCs) in the inflamed IBD mucosa $(n=30)$ and the mucosa of healthy controls $(H C)(n=10)$ before the treatment with TNFa inhibitors. The results are presented as the mean with the standard error of the mean (SEM). To compare means, we used an unpaired Student's t-test.

while the proportions of the $\mathrm{pDC}$ and $\mathrm{CD} 103^{+} \mathrm{DC}$ subsets remained unchanged (Table 6).

Responders to the treatment had a significantly higher proportion of cDCs in the inflamed mucosa 


\section{cDCs among LPMNCs}

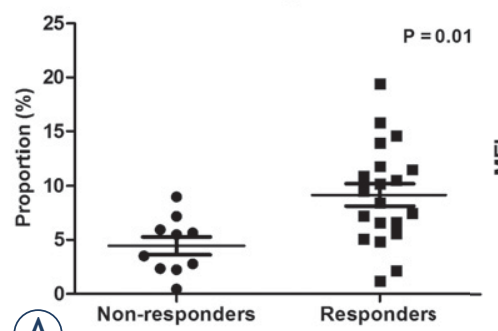

(A)

FIGURE 2. Predictors of the response to treatment. Inflammatory bowel disease patients who responded to TNFa inhibitors had a significantly higher proportion of (A) conventional dendritic cells (CDCs) with (B) higher expression of HLA-DR in the inflamed mucosa before treatment compared to nonresponders. CDC values are given as the percentage of CDCs among the lamina propria mononuclear cells and the expression of HLA-DR is shown as the mean fluorescence intensity (MFI) among CDCs. Horizontal lines indicate mean levels.

TABLE 5. Subpopulations of dendritic cells (DCs) in the uninflamed and inflamed inflammatory bowel disease (IBD) mucosa before the treatment with TNFa inhibitors

\begin{tabular}{lccc} 
& IBD-uninflamed & IBD-inflamed & p value \\
\hline pDC (\%) & $1.7(0.2)$ & $1.7(0.3)$ & 0.9 \\
CDC (\%) & $4.5(0.6)$ & $7.8(0.9)$ & 0.003 \\
CD86 (MFI) & $1483(212)$ & $1248(231)$ & 0.53 \\
HLA-DR (MFI) & $11965(767)$ & $10918(767)$ & 0.33 \\
CD103+ (\%) & $57.3(3.5)$ & $47.1(3.1)$ & 0.03 \\
CD103- (\%) & $42.3(3.4)$ & $52.8(3.2)$ & 0.02 \\
\hline
\end{tabular}

Proportion and median fluorescence intensity (MFI) of plasmacytoid DCs (pDCs) and conventional DCs (CDCs) in the inflamed and uninflamed IBD mucosa $(n=30)$ before the treatment with TNFa inhibitors. The results are presented as the mean with the standard error of the mean (SEM).

TABLE 6. SUbpopulations of dendritic cells (DCS) in inflamed inflammatory bowel disease (IBD) mucosa before and after the treatment with TNFa inhibitors

\begin{tabular}{lccc}
\hline & IBD-before & IBD-after & p value \\
\hline pDC (\%) & $1.7(0.3)$ & $1.3(0.2)$ & 0.32 \\
CDC (\%) & $7.8(0.9)$ & $4.5(0.9)$ & 0.01 \\
CD86 (MFI) & $1248(231)$ & $826(219)$ & 0.29 \\
HLA-DR (MFI) & $10918(767)$ & $12141(616)$ & 0.09 \\
CD103+ (\%) & $47.1(3.1)$ & $48.1(4.5)$ & 0.86 \\
CD103- (\%) & $52.8(3.2)$ & $50.7(4.8)$ & 0.75 \\
\hline
\end{tabular}

Proportion and median fluorescence intensity (MFI) of plasmacytoid DCs (pDCs) and conventional DCs (CDCs) in the inflamed IBD mucosa $(n=29)$ before and after the treatment with TNFa inhibitors. The results are presented as the mean with the standard error of the mean (SEM). To compare means, we used a paired Student's t-test.

before treatment compared to nonresponders. The expression of HLA-DR was also higher in the responders (Figure 2, Table 7).

There were no differences in these parameters between the two IBD types; however, only UC re- sponders had a higher proportion of the CD103+ DCs subset in the inflamed mucosa before the treatment compared to nonresponders (Table 8).

Patients with a higher proportion of cDCs in the inflamed mucosa before treatment were more likely to respond to the TNFa inhibitors. A total of $93 \%$ of patients with a proportion of cDCs above $7 \%$ responded to the therapy. The cut-off value of $6 \%$ was still $100 \%$ specific and $88 \%$ sensitive for the response to TNF- $\alpha$ inhibitors (Figure 3). Similarly, an HLA-DR MFI > 12450 had 90\% specificity and $45 \%$ sensitivity for the response (Figure 4 ).

\section{Discussion}

We prospectively investigated the in vivo effects of TNFa inhibitors on mucosal DCs in 30 IBD patients. This study confirmed previous observations on cDC changes after treatment with TNFa inhibitors. ${ }^{38}$ Our most important finding was that a proportion of cDCs above $7 \%$ in the inflamed IBD mucosa before treatment reliably predicted an endoscopic response to TNFa inhibitors, as 93\% of the patients with a proportion of $\mathrm{CDC}$ above this threshold responded to treatment.

To the best of our knowledge, this is the first study that investigates primary resistance to treatment with TNF $\alpha$ inhibitors from the perspective of DCs. Primary resistance to TNFa inhibitors is observed in up to $40 \%$ of patients with IBD and is associated with poor outcomes. ${ }^{28}$ Ineffective induction treatment can lead to serious adverse effects and high costs. ${ }^{28,39}$ Therefore, the identification of predictors of patient responsiveness to TNFa inhibitors, which would guide the selection of patients most likely to benefit from this therapy, is eagerly awaited.

The results of our study add important knowledge to this field as we identified significant differences in DC profiles in the pretreatment colonic mucosa of patients with primary resistance compared to that of patients who responded to the induction treatment with TNF- $\alpha$ inhibitors. The proportion of cDCs in the pretreatment colonic mucosa was higher in responders to TNFa inhibitors compared to nonresponders. Furthermore, in patients with primary resistance, there was a lack of activated cDCs, as evidenced by the lower expression of the activation marker HLA-DR. We also observed that responding patients had a higher proportion of the CD103+ DC subset. This was particularly pronounced in patients with UC. We predicted the response to TNFa inhibitors with $93 \%$ specificity 
based on the DC profile of the pretreatment mucosa. Our results, if confirmed in a larger cohort, are likely to guide treatment decisions. Patients with an unfavourable DC profile could expect a greater benefit from other non-TNFa-based treatments for IBD, such as ustekinumab or vedolizumab. . $^{40,41}$

The strengths of our study are the prospective inclusion of patients with endoscopically confirmed inflammation in the colonic mucosa at baseline and the use of the robust endpoint of mucosal healing after induction treatment, which has been shown to be associated with long-term remission in patients with IBD. ${ }^{42,43}$ These conclusions are further strengthened by our finding that objective markers of inflammation (CRP and faecal calprotectin concentrations) before treatment had no predictive value for the response to TNF $\alpha$ inhibitors. Therefore, we believe that changes in the DC profile after the successful induction of mucosal healing with TNFa inhibitors predict long-term control of disease.

Our data also showed that CD and UC patients display the same DC imbalance in the inflamed intestinal mucosa compared to mucosa of healthy controls, which is consistent with previously published data. ${ }^{44}$

The inclusion of healthy controls enabled us to study differences in healthy and diseased colonic mucosa. We observed a higher frequency of the CD103- DC subset and an inverse ratio of the $\mathrm{CD} 13^{+} / \mathrm{CD}^{-} 3^{-} \mathrm{DC}$ subsets in the inflamed mucosa compared to the mucosa of the healthy controls. The reduced proportion of the $\mathrm{CD} 103^{+} \mathrm{DC}$ subset reflects the disturbance in gut tolerance and explains the high levels of proinflammatory cytokines, such as IL-12 and IL-23, in the inflamed mucosa of patients with IBD..$^{45-50}$ In line with this, we observed a shift towards a more favorable

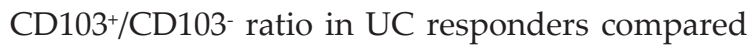
to UC nonresponders. The successful induction of mucosal healing in patients with $C D$ was not associated with changes in the $\mathrm{CD} 103^{+} / \mathrm{CD} 103^{-} \mathrm{DC}$ ratio. This underlines the different pathological mechanisms of the two diseases. ${ }^{5,14,51}$

In our study, patients with more activated cDCs in the pretreatment colonic mucosa responded better to TNFa inhibitors than patients with a lower proportion of cDCs in the colonic mucosa. The increased amount of activated cDCs in responders could be a reflection of a higher local amount of mucosal TNFa in responders compared to nonresponders. A possible explanation for the favourable response to TNFa inhibitors in patients with a high local concentration of TNFa was provided by Yarur et al. ${ }^{52}$, who observed increased local accu-

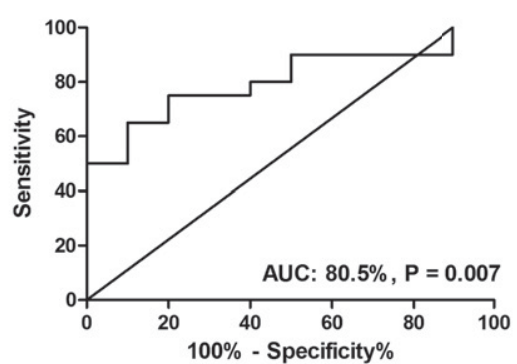

FIGURE 3. ROC curve analysis identified the proportion of conventional dendritic cells as a predictor of the response to TNFa inhibitors. Patients with a proportion of conventional dendritic cells above $7 \%$ responded to treatment.

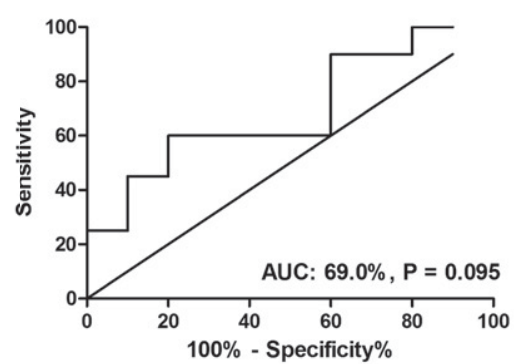

FIGURE 4. ROC curve analysis of conventional dendritic cell HLA-DR expression in the colonic mucosa before treatment for the prediction of the response to the induction treatment with TNF-a inhibitors. All patients with an HLA-DR MFI above 12450 responded to the treatment.
TABLE 7. Subpopulations of dendritic cells (DCs) in the inflamed inflammatory bowel disease (IBD) mucosa in responders and nonresponders before the treatment with TNFa inhibitors

\begin{tabular}{lccc}
\hline & Responders & Nonresponders & p value \\
\hline IBD & & & \\
PDC (\%) & $1.9(0.4)$ & $1.3(0.4)$ & 0.3 \\
CDC (\%) & $9.2(1.0)$ & $4.4(0.8)$ & 0.01 \\
CD86 (MFI) & $1436(332)$ & $785(177)$ & 0.2 \\
HLA-DR (MFI) & $12152(868)$ & $8838(1286)$ & 0.04 \\
CD103+(\%) & $51.0(3.7)$ & $42.5(5.5)$ & 0.2 \\
CD103. (\%) & $48.8(3.8)$ & $57.5(5.5)$ & 0.2 \\
\hline
\end{tabular}

Proportion and median fluorescence intensity (MFI) of plasmacytoid DCs (pDCs) and conventional DCs (CDCs) in the inflamed IBD mucosa of responders and nonresponders $(n=29)$ before the treatment with TNFa inhibitors. The results are presented as the mean with the standard error of the mean (SEM). To compare means, we used an unpaired Student's t-test.

mulation of TNFa inhibitors in patients with more TNFa expression in inflamed colonic tissue. In our patients who did not respond, inflammation could be driven by non-TNFa mediators, such as IL-23. In such cases, IL-23, which maintains chronic inflammation through the Th17 cell pathway, could be a better treatment target. ${ }^{40,53}$ Interestingly, many genetic polymorphisms linked to primary resistance to TNFa inhibitors have been identified in the Th17 pathway. ${ }^{54}$

The CD86 costimulatory molecule primes T cells during antigen presentation and represents a marker of DC maturation. ${ }^{55}$ It is therefore not surprising that we confirmed higher expression of this molecule in IBD patients compared to healthy controls. ${ }^{56}$ This is also in agreement with our observation that CD86 expression decreased more 
TABLE 8. Subpopulations of dendritic cells (DCs) in the inflamed ulcerative colitis and Crohn's disease mucosa in responders and nonresponders before the treatment with TNFa inhibitors

\begin{tabular}{lccc}
\hline & Responders & Nonresponders & p value \\
\hline Ulcerative colitis & & & \\
pDC (\%) & $2.5(0.6)$ & $1.7(0.6)$ & 0.9 \\
CDC (\%) & $10.1(1.5)$ & $4.7(1.2)$ & 0.04 \\
CD86 (MFI) & $1595(523)$ & $552(40)$ & 0.2 \\
HLA-DR (MFI) & $12182(3613)$ & $6693(3614)$ & 0.01 \\
CD103+ (\%) & $61.4(7.0)$ & $34.8(6.5)$ & 0.02 \\
CD103- (\%) & $38.4(7.1)$ & $65.2(2.7)$ & 0.02 \\
Crohn's disease & & & \\
PDC (\%) & $1.6(0.4)$ & $0.9(0.3)$ & 0.2 \\
CDC (\%) & $9.7(1.6)$ & $4.2(1.0)$ & 0.04 \\
CD86 (MFI) & $1452(434)$ & $1019(335)$ & 0.5 \\
HLA-DR (MFI) & $13152(1319)$ & $10983(1368)$ & 0.3 \\
CD103+ (\%) & $50.8(4.9)$ & $50.2(9.9)$ & 0.9 \\
CD103. (\%) & $49.2(4.5)$ & $49.8(9.9)$ & 0.9 \\
\hline
\end{tabular}

Proportion and median fluorescence intensity (MFI) of plasmacytoid DCs (pDCs) and conventional DCs (CDCS) in the inflamed inflammatory bowel disease (IBD) mucosa of responders and nonresponders with ulcerative colitis and Crohn's disease $(n=29)$ before the treatment with TNFa inhibitors. The results are presented as the mean with the standard error of the mean (SEM). To compare means, we used an unpaired Student's t-test.

in responders to TNFa inhibitors compared to nonresponders (although our finding needs further conformation due to the limited sample size, which possibly prevented us from reaching statistical significance). ${ }^{57}$ Interestingly, we also found increased expression of CD86 in macroscopically uninflamed segments of colon from patients with IBD compared to those from healthy controls - a finding that underlines that chronic inflammation is also present in colonic segments that appear endoscopically normal (Table 4).

In our study, we confirmed more pDCs in patients with CD and UC compared to healthy controls. ${ }^{20,58-60}$ However, we did not observe any differences in the amount of pDCs in the inflamed mucosa compared to the uninflamed mucosa in patients with IBD. Additionally, TNFa inhibitors did not affect the proportion of pDCs in the colonic mucosa.

The small number of patients included in this study represents a limitation, which we tried to mitigate by assessing the treatment with the robust and objective criteria of mucosal healing instead of clinical parameters. This eliminated the placebo effect, which has been observed in many IBD studies in up to $30 \%$ of patients. Fifty-seven percent of our patients were being treated with concomitant immunosuppressants at the time of study inclusion. This could have influenced our results; however, the dose of the immunosuppressants was stable during the induction treatment up to the time point of the evaluation endoscopy. Additionally, a recent meta-analysis did not show any impact of immunosuppressants on DC maturation. ${ }^{61}$

The second limitation of our study is that the IBD group (on average 39 yrs old) and healthy controls (on average 58 yrs old) were not completely age-matched. There are very few reports evaluating age-related DC numbers in intestinal tissue. In children, Teig et al. ${ }^{62}$ reported a change in the numbers of different DC subpopulations according to age. However, Bella et al. ${ }^{63}$ did not find any significant age-related changes in the numbers of DC subpopulations, but DCs from elderly individuals (older than $60 \mathrm{yrs}$ ) were more mature and impaired in the production of IL-12 compared to those from younger individuals. In our study, DCs from the healthy control group expressed fewer markers of maturation (CD86). We believe that age differences between our groups did not influence the proportions and phenotypes of the DCs.

Our findings are limited to colonic DCs since we did not include small bowel biopsies in the analysis. This is important to note, as it has been shown that ileal involvement represents a distinct IBD phenotype. ${ }^{64,65}$

In conclusion, we prospectively investigated the effect of TNFa inhibitors on colonic DC profiles in 30 IBD patients. Our findings of differential pretreatment DC profiles and differential expression of HLA-DR in responders compared to nonresponders to TNFa inhibitors add important additional insight into the mechanism of primary resistance to TNFa inhibitors.

We identified a pretreatment mucosal DC profile that was linked to successful mucosal healing after induction therapy with TNFa inhibitors. According to this profile, we were able to predict the response to TNFa inhibitors with $93 \%$ specificity and $88 \%$ sensitivity.

The pretreatment mucosal DC profile may be a powerful tool to predict the response to TNFa inhibitors and thus assist clinicians in choosing the most effective treatment for individual patients.

\section{Acknowledgement}

The study was supported by the Slovene Ministry of Education and Science grant P3-0083. 


\section{References}

1. Geremia A, Biancheri P, Allan P, Corazza GR, Di Sabatino A. Innate and adaptive immunity in inflammatory bowel disease. Autoimmun Rev 2014; 13: 3-10. doi: 10.1016/j.autrev.2013.06.004

2. Kmiec Z, Cyman M, Slebioda TJ. Cells of the innate and adaptive immunity and their interactions in inflammatory bowel disease. Adv Med Sci 2017; 62: 1-16. doi: 10.1016/j.advms.2016.09.001

3. Niess JH. Role of mucosal dendritic cells in inflammatory bowel disease. World J Gastroenterol 2008; 14: 5138-48. doi: 10.3748/wjg.14.5138

4. Rutella S, Locatelli F. Intestinal dendritic cells in the pathogenesis of inflammatory bowel disease. World J Gastroenterol 2011; 17: 3761-75. doi: 10.3748/wjg.v17.i33.3761

5. Cader MZ, Kaser A. Recent advances in inflammatory bowel disease: mucosal immune cells in intestinal inflammation. Gut 2013; 62: 1653-64. doi: 10.1136/gutjnl-2012-303955

6. Kushwah R, Hu J. Complexity of dendritic cell subsets and their function in the host immune system. Immunology 2011; 133: 409-19. doi: 10.1111/j.1365-2567.2011.03457.x

7. Alloatti A, Kotsias F, Magalhaes JG, Amigorena S. Dendritic cell maturation and cross-presentation: timing matters! Immunol Rev 2016; 272: 97-108. doi: 10.1111/imr.12432

8. Stockwin LH, McGonagle D, Martin IG, Blair GE. Dendritic cells: immunological sentinels with a central role in health and disease. Immunol Cell Biol 2000; 78: 91-102. doi: 10.1046/j.1440-1711.2000.00888.x

9. Abbas A, Lichtman A, Pillai S. Basic immunology: functions and disorders of the immune system. $5^{\text {th }}$ Edition. St. Louis, Missouri: Elsevier; 2015.

10. Sallusto $F$, Lanzavecchia A. The instructive role of dendritic cells on T-cell responses. Arthritis Res 2002; 4: S127-32. doi: 10.1186/ar567

11. Blanco P, Palucka AK, Pascual V, Banchereau J. Dendritic cells and cytokines in human inflammatory and autoimmune diseases. Cytokine Growth Factor Rev 2008; 19: 41-52. doi: 10.1016/j.cytogfr.2007.10.004

12. Axelrad JE, Lichtiger S, Yajnik V. Inflammatory bowel disease and cancer: the role of inflammation, immunosuppression, and cancer treatment. World J Gastroenterol 2016; 22: 4794-801. doi: 10.3748/wjg.v22.i20.4794

13. Coombes JL, Powrie F. Dendritic cells in intestinal immune regulation. Nat Rev Immunol 2008; 8: 435-46. doi: 10.1038/nri2335

14. Choy MC, Visvanathan K, De Cruz P. An overview of the innate and adaptive immune system in inflammatory bowel disease. Inflamm Bowel Dis 2017; 23: 2-13. doi: 10.1097/mib.0000000000000955

15. Persson EK, Scott CL, Mowat AM, Agace WW. Dendritic cell subsets in the intestinal lamina propria: ontogeny and function. Eur J Immunol 2013; 43: 3098-107. doi: 10.1002/eji.201343740

16. Schiavi E, Smolinska S, O'Mahony L. Intestinal dendritic cells. Curr Opin Gastroenterol 2015; 31: 98-103. doi: 10.1097/mog.0000000000000155

17. Vitale S, Strisciuglio C, Pisapia L, Miele E, Barba P, Vitale A, et al. Cytokine production profile in intestinal mucosa of paediatric inflammatory bowel disease. PLoS One 2017; 12: e0182313. doi: 10.1371/journal.pone.0182313

18. Baumgart DC, Metzke D, Schmitz J, Scheffold A, Sturm A, Wiedenmann B, et al. Patients with active inflammatory bowel disease lack immature peripheral blood plasmacytoid and myeloid dendritic cells. Gut 2005; 54: 228-36. doi: 10.1136/gut.2004.040360

19. Middel P, Raddatz D, Gunawan B, Haller F, Radzun HJ. Increased number of mature dendritic cells in Crohn's disease: evidence for a chemokine mediated retention mechanism. Gut 2006; 55: 220-7. doi: 10.1136/ gut.2004.063008

20. Baumgart DC, Metzke D, Guckelberger O, Pascher A, Grotzinger C Przesdzing I, et al. Aberrant plasmacytoid dendritic cell distribution and function in patients with Crohn's disease and ulcerative colitis. Clin Exp Immunol 2011; 166: 46-54. doi: 10.1111/j.1365-2249.2011.04439.x

21. Sanchez-Munoz F, Dominguez-Lopez A, Yamamoto-Furusho JK. Role of cytokines in inflammatory bowel disease. World J Gastroenterol 2008; 14: 4280-8. doi: 10.3748/wjg.14.4280

22. Van Deventer SJ. Tumour necrosis factor and Crohn's disease. Gut 1997; 40: 443-8. doi: 10.1136/gut.40.4.443
23. Sands BE, Kaplan GG. The role of TNFalpha in ulcerative colitis. I Clin Pharmacol 2007; 47: 930-41. doi: 10.1177/0091270007301623

24. Levin AD, Wildenberg ME, van den Brink GR. Mechanism of action of antiTNF therapy in inflammatory bowel disease. J Crohns Colitis 2016; 10: 98997. doi: 10.1093/ecco-jcc/jjw053

25. Nielsen $\mathrm{OH}$, Ainsworth MA. Tumor necrosis factor inhibitors for inflammatory bowel disease. N Engl J Med 2013; 369: 754-62. doi: 10.1056/ NEJMct1209614

26. Chapman CG, Rubin DT. The potential for medical therapy to reduce the risk of colorectal cancer and optimize surveillance in inflammatory bowel disease. Gastrointest Endosc Clin N Am 2014; 24: 353-65. doi: 10.1016/j. giec.2014.03.008

27. Andersen NN, Jess T. Has the risk of colorectal cancer in inflammatory bowe disease decreased? World J Gastroenterol 2013; 19: 7561-8. doi: 10.3748/ wjg.v19.i43.7561

28. Kopylov U, Seidman E. Predicting durable response or resistance to antitumor necrosis factor therapy in inflammatory bowel disease. Therap Adv Gastroenterol 2016; 9: 513-26. doi: 10.1177/1756283×16638833

29. Gomollon F, Dignass A, Annese V, Tilg H, Van Assche G, Lindsay JO, et al. 3rd European evidence-based consensus on the diagnosis and management of Crohn's disease 2016: part 1: diagnosis and medical management. J Crohns Colitis 2017; 11: 3-25. doi: 10.1093/ecco-jcc/jjw168

30. Magro F, Gionchetti P, Eliakim R, Ardizzone S, Armuzzi A, Acosta MB, et al Third european evidence-based consensus on diagnosis and management of ulcerative colitis. Part 1: definitions, diagnosis, extra-intestinal manifestations, pregnancy, cancer surveillance, surgery, and ileo-anal pouch disorders. J Crohns Colitis 2017; 11: 649-70. doi: 10.1093/ecco-jcc/jjx008

31. Best WR. Predicting the Crohn's disease activity index from the HarveyBradshaw Index. Inflamm Bowel Dis 2006; 12: 304-10. doi: 10.1097/01. MIB.0000215091.77492.2a

32. Walmsley RS, Ayres RC, Pounder RE, Allan RN. A simple clinical colitis activity index. Gut 1998; 43: 29-32. doi: 10.1136/gut.43.1.29

33. Daperno M, D'Haens G, Van Assche G, Baert F, Bulois P, Maunoury V, et al. Development and validation of a new, simplified endoscopic activity score for Crohn's disease: the SES-CD. Gastrointest Endosc 2004; 60: 505-12. doi: 10.1016/S0016-5107(04)01878-4

34. Buchner AM, Lichtenstein GR. How to assess and document endoscopies in IBD patients by including standard scoring systems. Inflamm Bowel Dis 2016; 22: 1010-9. doi: 10.1097/mib.0000000000000649

35. Côté-Daigneault J, Bouin M, Lahaie R, Colombel JF, Poitras P. Biologics in inflammatory bowel disease: what are the data? United Eur Gastroenterol $J$ 2015; 3: 419-28. doi: 10.1177/2050640615590302

36. Scott $\mathrm{CL}$, Wright PB, Milling SW, Mowat AM. Isolation and identification of conventional dendritic cell subsets from the intestine of mice and men Methods Mol Biol 2016; 1423: 101-18. doi: 10.1007/978-1-4939-3606-9_7

37. Roe MM, Swain S, Sebrell TA, Sewell MA, Collins MM, Perrino BA, et al. Differential regulation of $\mathrm{CD} 103$ (alphaE integrin) expression in human dendritic cells by retinoic acid and Toll-like receptor ligands. J Leukoc Biol 2017; 101: 1169-80. doi: 10.1189/jlb.1MA0316-131R

38. Dige A, Magnusson MK, Ohman L, Hvas CL, Kelsen J, Wick MJ, et al. Reduced numbers of mucosal DR(int) macrophages and increased numbers of $\mathrm{CD} 103(+)$ dendritic cells during anti-TNF-alpha treatment in patients with Crohn's disease. Scand J Gastroenterol 2016; 51: 692-9. doi: 10.3109/00365521.2015.1134649

39. Zampeli E, Gizis M, Siakavellas SI, Bamias G. Predictors of response to anti-tumor necrosis factor therapy in ulcerative colitis. World J Gastrointest Pathophysiol 2014; 5: 293-303. doi: 10.4291/wjgp.v5.i3.293

40. Feagan BG, Sandborn WJ, Gasink C, Jacobstein D, Lang Y, Friedman JR, et al. Ustekinumab as induction and maintenance therapy for Crohn's disease. $N$ Engl J Med 2016; 375: 1946-60. doi: 10.1056/NEJMoa1602773

41. McLean LP, Shea-Donohue T, Cross RK. Vedolizumab for the treatment of ulcerative colitis and Crohn's disease. Immunotherapy 2012; 4: 883-98. doi: $10.2217 /$ imt.12.85

42. Colombel JF, Rutgeerts P, Reinisch W, Esser D, Wang Y, Lang Y, et al. Early mucosal healing with infliximab is associated with improved long-term clinical outcomes in ulcerative colitis. Gastroenterology 2011; 141: 1194-201. doi: 10.1053/j.gastro.2011.06.054 
43. Baert F, Moortgat L, Van Assche G, Caenepeel P, Vergauwe P, De Vos M, et al. Mucosal healing predicts sustained clinical remission in patients with earlystage Crohn's disease. Gastroenterology 2010; 138: 463-8. doi: 10.1053/j. gastro.2009.09.056

44. Magnusson MK, Brynjólfsson SF, Dige A, Uronen-Hansson H, Börjesson LG, Bengtsson JL, et al. Macrophage and dendritic cell subsets in IBD: ALDH(+) cells are reduced in colon tissue of patients with ulcerative colitis regardless of inflammation. Mucosal Immunol 2016; 9: 171-82. doi: 10.1038/ mi.2015.48

45. Annacker $\mathrm{O}$, Coombes JL, Malmstrom V, Uhlig HH, Bourne T, JohanssonLindbom B, et al. Essential role for CD103 in the T cell-mediated regulation of experimental colitis. J Exp Med 2005; 202: 1051-61. doi: 10.1084/ jem.20040662

46. Scott CL, Aumeunier AM, Mowat AM. Intestinal CD103+ dendritic cells: master regulators of tolerance? Trends Immunol 2011; 32: 412-9. doi: 10.1016/j.it.2011.06.003

47. del Rio ML, Bernhardt G, Rodriguez-Barbosa II, Forster R. Development and functional specialization of CD103+ dendritic cells. Immunol Rev 2010; 234: 268-81. doi: 10.1111/j.0105-2896.2009.00874.x

48. Cerovic V, Houston SA, Scott CL, Aumeunier A, Yrlid U, Mowat AM, et al. Intestinal CD103(-) dendritic cells migrate in lymph and prime effector $\mathrm{T}$ cells. Mucosal Immunol 2013; 6: 104-13. doi: 10.1038/mi.2012.53

49. Ruane DT, Lavelle EC. The role of $\mathrm{CD} 103(+)$ dendritic cells in the intestinal mucosal immune system. Front Immunol 2011; 2: 25. doi: 10.3389/ fimmu.2011.00025

50. Iliev ID, Spadoni I, Mileti E, Matteoli G, Sonzogni A, Sampietro GM, et al. Human intestinal epithelial cells promote the differentiation of tolerogenic dendritic cells. Gut 2009; 58: 1481-9. doi: 10.1136/gut.2008.175166

51. Annaházi A, Molnár T. Pathogenesis of ulcerative colitis and Crohn's disease: similarities, differences and a lot of things we do not know yet. J Clin Cell Immunol 2014; 5: 253. doi: 10.4172/2155-9899.1000253

52. Yarur AJ, Jain A, Sussman DA, Barkin JS, Quintero MA, Princen F, et al. The association of tissue anti-TNF drug levels with serological and endoscopic disease activity in inflammatory bowel disease: the ATLAS study. Gut 2016; 65: 249-55. doi: 10.1136/gutjnl-2014-308099

53. Abraham C, Dulai PS, Vermeire S, Sandborn WJ. Lessons learned from trials targeting cytokine pathways in patients with inflammatory bowel diseases. Gastroenterology 2017; 152: 374-88. doi: 10.1053/j.gastro.2016.10.018

54. Prieto-Perez R, Almoguera B, Cabaleiro T, Hakonarson H, Abad-Santos F. Association between genetic polymorphisms and response to anti-TNFs in patients with inflammatory bowel disease. Int J Mol Sci 2016; 17: 225. doi: 10.3390/ijms17020225

55. Radwan P, Radwan-Kwiatek K, Tabarkiewicz J, Radej S, Rolinski J. Enhanced phenotypic and functional maturation of monocyte-derived dendritic cells from patients with active Crohn's disease and ulcerative colitis. J Physiol Pharmacol 2010; 61: 695-703. PMID: 21224500

56. Vuckovic S, Florin $\mathrm{TH}$, Khalil D, Zhang MF, Patel K, Hamilton I, et al. CD40 and CD86 upregulation with divergent CMRF44 expression on blood dendritic cells in inflammatory bowel diseases. Am J Gastroentero/ 2001; 96: 2946-56. doi: 10.1111/j.1572-0241.2001.04686.x

57. Hart AL, Al-Hassi HO, Rigby RJ, Bell SJ, Emmanuel AV, Knight SC, et al. Characteristics of intestinal dendritic cells in inflammatory bowel diseases. Gastroenterology 2005; 129: 50-65. doi: 10.1053/j.gastro.2005.05.013

58. Lombardi VC, Khaiboullina SF. Plasmacytoid dendritic cells of the gut: relevance to immunity and pathology. Clin Immunol 2014; 153: 165-77. doi: 10.1016/j.clim.2014.04.007

59. Hostmann A, Kapp K, Beutner M, Ritz JP, Loddenkemper C, Ignatius R, et al Dendritic cells from human mesenteric lymph nodes in inflammatory and non-inflammatory bowel diseases: subsets and function of plasmacytoid dendritic cells. Immunology 2013; 139: 100-8. doi: 10.1111/imm.12060

60. Knight SC. Dendritic cell-T-cell circuitry in health and changes in inflammatory bowel disease and its treatment. Dig Dis 2016; 34: 51-7. doi: $10.1159 / 000442926$

61. Lagaraine C, Lebranchu Y. Effects of immunosuppressive drugs on dendritic cells and tolerance induction. Transplantation 2003; 75: 37s-42s. doi: 10.1097/01.tp.0000067950.90241.1d
62. Teig N, Moses D, Gieseler S, Schauer U. Age-related changes in human blood dendritic cell subpopulations. Scand J Immunol 2002; 55: 453-7. doi: 10.1046/j.1365-3083.2002.01068.x

63. Bella SD, Bierti L, Presicce P, Arienti R, Valenti M, Saresella M, et al. Peripheral blood dendritic cells and monocytes are differently regulated in the elderly. Clin Immunol 2007; 122: 220-8. doi: 10.1016/j.clim.2006.09.012

64. Dzutsev A, Hogg A, Sui Y, Solaymani-Mohammadi S, Yu H, Frey B, et al. Differential T cell homing to colon vs. small intestine is imprinted by local CD11c(+) APCs that determine homing receptors. J Leukoc Biol 2017; 102: 1381-8. doi: 10.1189/jlb.1A1116-463RR

65. Cleynen I, Boucher G, Jostins L, Schumm LP, Zeissig S, Ahmad T, et al. Inherited determinants of Crohn's disease and ulcerative colitis phenotypes: a genetic association study. Lancet 2016; 387: 156-67. doi: 10.1016/s01406736(15)00465-1 